\section{Grey and Red Squirrels in Britain.}

$\mathrm{F}^{\mathrm{O}}$

$\mathrm{R}$ years, naturalists have been familiar in a general way with the aptitude shown by the American grey squirrel for colonising parts of Britain, with the controversy regarding the harmfulness or otherwise of its habits, and the allegation that it has driven the native red squirrel before it. Never before, however, has an attempt at all comparable with that of Mr. A. D. Middleton* been made to collect all the facts regarding this undesirable alien before passing judgment upon it. The paper also contains information relating to the fluctuations and decline of the red squirrel in Great Britain, so important that this species, too, might well have shared a place in the title.

So long ago as 1830 , the grey squirrel was known in Montgomeryshire and Denbighshire, but the present state of affairs is almost wholly due to introductions since 1890. Thirty-three different introductions, involving twenty-nine localities, have been traced, and the sum of their results is astonishing. By 1930 the grey squirrel, according to Mr. Middleton's thorough census, had populated a total area of approximately 13,350 square miles, mainly in southern England, Cheshire, and Yorkshire, and there is every reason to believe that it will eventually cover the whole country, with the possible exception of mountainous districts such as northern Scotland.

Although much of the evidence regarding the food of the creature is unbalanced or biased, there can be little doubt that it is a nuisance in Great Britain. Green food, fruit, and nuts form the major part of the food supply, but it robs birds' nests of their eggs and young, and the damage it does to woodland by biting off young shoots and leaders, and by peeling or ringing the bark of young trees (the present writer has seen branches of old trees girdled as well), is enough to condemn it in the eyes of every forester. The fact that at least 750,000 acres of new forest are in progress of being planted suggests that here lies a potential food-store to encourage fresh colonisation, and points to a new danger in the presence of the grey squirrel.

It has often been said that the grey squirrel kills out or drives away the native red squirrel, but no direct evidence of such antagonism has been forthcoming. The present writer agrees entirely with Mr. Middleton's view that in many areas (in Scotland, at any rate) the red squirrel has declined, apart altogether from the presence of its possible rival. Nevertheless, the red squirrel almost holds its own in some of the extensive northern forests, and it must surprise many readers to learn that the Highland Squirrel Club, in a limited area confined to thirty-six estates in the north of Scotland, destroyed in the years from 1903 to $1929,82,000$ squirrels.

In considering the future possibilities of the introduced grey squirrel as a serious economic pest, it is well to remember that, so far as Scotland is concerned, the red squirrel itself is a species that was reintroduced after it had almost or wholly disappeared, about the beginning of the nineteenth century. One would imagine that the tale of the risk of introductions was written plain enough for anyone to see, and yet the process goes merrily on : within the last few years the musk-rat has been added to the Scottish list of aliens likely to call down future curses upon the heads of its thoughtless or ignorant sponsors.

\section{J. R.}

* A. D. Middleton, "The Ecology of the American Grey Squirrel (Seiurus carolinensis) in the British Isles", Proc. Zool. Soc. London part 3, p. $809 ; 1930$.

\section{Birthdays and Research Centres.}

April 2, r 853.-Prof. P. Phillips Bedson, emeritus professor of chemistry, Armstrong College, New castle-on-Tyne.

In describing some experiments on the gases enclosed in certain varieties of coal dust, at a meeting of the North of England Institute of Mining and Mechanical Engineers in 1888, I directed attention to the fact that the inflammable constituent appeared to contain other members of the paraffin series in addition to methane (marsh gas). In the discussion, the late Sir Charles Parsons suggested that the examination of the gases released from the coal yielding such dust, by grinding it in a vacuum, might afford information on the composition of these gases. In the session 1913-14, I had contrived a method of testing this suggestion, but was unable to complete the investigation, as on the outbreak of War the buildings of Armstrong College were taken over by the military authorities, and when possession was regained in 1919 opportunity for pursuing the investigations further did not present itself. In 1921, I resigned from the professorship of chemistry in Armstrong College and came to reside in the south of England. The repetition of this work, in the light of the influence of these gases on the ignitability of mixtures of air and coal dust, and the examination of firedamp for the presence of other paraffin hydrocarbons than methane, is a problem to which attention might usefully be given.

April 5, I 865.-Sir John BRETLAND FARMER, F.R.S., emeritus professor of botany and formerly director of biological laboratories, Imperial College of Science and Technology, London.

Amongst the various lines of research in which $\mathrm{I}$ happen to have been specially interested, there are few, I think, which offer more attractive possibilities than those which concern excretion, in the larger sense of the term. The mechanism by which sugar in a concentrated state is excreted in nectaries (and by various other non-floral glands), though doubtless not too easy to investigate, is one which can surely yield a much larger harvest on the way towards its solution than it has yet produced. Of course, it may be said that the whole matter is a question of energy - and this observation was actually made to me by a very eminent physiologist of his day, some twenty years ago. But it is clear that very little is thereby really gained. No doubt the energy for moving a train is derived from the combustion of coal in the engine, but that tells nothing of the machinery and of the steps whereby the energy derived from oxidation of coal is enabled to be utilised for moving the train.

A set of problems akin-perhaps more than is at first sight obvious - to those just referred to, concern the internal movement of water within the higher plant, wherever protoplasm takes a hand in the matter. Much has from time to time been written about ' root pressure', but how much is really known as to the Wesen of root pressure? It is a subject I have myself pursued, not too successfully, for a number of years, though I did find a few side tracks which seemed to be more hopeful than the main route. It would be useful to know to what extent and under what precise conditions the sugars derived from the surrounding living parenchymatous cells find their way into the dead wood vessels. Semipermeability has really ceased to be a rigorous dogma where living protoplasm is concerned. It is another example of the truth that ' circumstances alter 
cases'. By that same track we get into closer touch with the problems of spring bleeding so characteristic of many trees, etc., though in different degrees, and varying under different external conditions.

In concluding the few remarks, which have filled more than the space allotted to me, may $\mathrm{I}$ venture to suggest that many of our younger botanists, particularly those who are physiologically-minded, might profitably acquire a larger horticultural knowledge of growing plants than most of them seem to possess? The problems of the garden are numerous and profitable, but a practical fore-knowledge of the garden and its denizens is essential for their recognition; the garden is a more fertile source of inspiration and research than many shelves of 'pickle' bottles.

April 5, I868.--R. H. BuRNe, F.R.S., physiological curator at the Royal College of Surgeons, London.

During the past few years I have been much interested in certain peculiarities of the lymphatic system of Teleostean fishes, which suggest that in the early stages of its differentiation the lymphatic system comprised both afferent and efferent factors comparable to arteries and veins. I am now carrying on similar researches into the constitution of the pseudolymph system in the skin of Elasmobranchs, in the hope of determining the nature of the 'cutaneous veins and their morphological relationship to the rest of the vascular system and to the cutaneous lymphatics of other fishes.

April II, I890.- Prof. E. K. Rideat, F.R.S., professor of colloid physics in the University of Cambridge.

We are engaged in determining the potential difference existing at air-liquid interfaces and also at gasmetal interfaces. This potential difference is modified to a marked extent by the presence of a unimolecular film, for example, a fatty acid film on a water surface or alcohol on a gold surface. These changes caused by films of different types, of different surface concentrations, of films undergoing chemical reaction or simple solution or evaporation, can be measured with considerable accuracy.

\section{Societies and Academies.}

\section{LONDON.}

Institute of Metals (Annual General Meeting), Mar. 12. -C. E. Pearson and J. A. Smythe: The influence of pressure and temperature on the extrusion of metals. The paper describes experiments made in a small press on the extrusion-phenomena of the metals lead, cadmium, bismuth, and tin. The chief part of the work is concerned with the determination, under precise control, of the relationship between the rate of extrusion, pressure, and temperature. This relationship is expressed in a series of curves, the mathematical treatment of which is indicated.- J. D. Grogan and D. Clayton: Dimensional stability of heat-treated aluminium alloys. Careful search has failed to reveal the occurrence of secular change in certain commercial heat-treated aluminium alloys, subsequent to the completion of the normal ageing process. Serious dimensional changes occur when machining operations are carried out on material quenched in cold water.-D. Hanson and M. A. Wheeler : The deformation of metals under prolonged loading. (1) The flow and fracture of aluminium. The principal method used consisted in examining the changes in microstructure of polished specimens, subjected to static stresses at room and elevated temperatures. The extension under a prolonged load that will ultimately break the metal may be considered as consisting of a period of primary extension, during which the rate of flow diminishes; a period during which flow is very slow or even suspended; and a period during which the extension again increases continuously until fracture occurs. Failure under creep conditions may be due to intercrystalline eracking, resumption of slipping within the original crystals, or recrystallisation. Failure of aluminium under various conditions was examined. Rupture of the crystals probably commences along slip planes formed at an early stage in the deformation of the metal.-K. L. Meissner : The effect of artificial ageing upon the resistance of super-duralumin to corrosion by sea-water. A different 'pock-form corrosion', combined with highly deleterious effect on the tensile properties, and primarily caused by intercrystalline corrosion, was found in an intermediate range of annealing temperature at $125^{\circ}-145^{\circ} \mathrm{C}$., and especially at $140^{\circ} \mathrm{C}$.S. L. Archbutt and W. E. Prytherch: Investigation of the effects of impurities on copper. (7) The effect of antimony on copper.--(8) The combined effect of antimony and arsenic on copper. In the antimony copper series, alloys containing up to 0.85 per cent antimony have been studied, and in the arsenicantimony-copper series, up to 0.5 per cent of each impurity together. In the former series, alloys containing up to 0.47 per cent antimony withstood hot rolling and up to 0.85 per cent cold rolling from cast billets. An alloy containing 0.85 per cent antimony was hot short. In the latter series all compositions withstood rolling either hot or cold. Antimony is highly soluble in solid copper, and small additions of this element to copper low in oxygen are found to improve the tensile strength at ordinary temperatures and at $250^{\circ} \mathrm{C}$. the fatigue properties, and to raise the softening temperature (of cold-worked material), without impairing ductility or toughness. Copper low in oxygen, containing antimony and arsenic together, appears to withstand hot rolling better than with antimony alone. The mechanical properties of copper low in oxygen are improved by small additions of antimony and arsenic together. Both impurities lower the electrical conductivity of copper. L. J. Brice: Some properties of siliconaluminium-bronzes'. The paper describes the results of a detailed study of the Brinell hardness, mechanical properties, and microstructure of three typical aluminium-copper alloys, containing respectively $5 \cdot 0,7 \cdot 25$, and $10 \cdot 0$ per cent aluminium, with the addition to each of up to 5.0 per cent silicon. - Owen W. Ellis : The rolling of alloys of copper and phosphorus containing up to 5 per cent of phosphorus. The plain phosphorus-copper alloys can all be successfully hot-rolled at $450^{\circ}-650^{\circ} \mathrm{C}$. to produce strip $0.021 \mathrm{in}$. thick, provided that only small reductions of thickness are made at each stage of the rolling. In this way the copper-copper phosphide eutectic structure is thoroughly broken up, and the strip can then be cold-rolled to $0.015 \mathrm{in}$.

\section{Paris.}

Academy of Sciences, Feb. 16.-Jean Rey: The conditions for the best utilisation of the energy of warm water, natural and industrial.--Georges Claude : Remarks. on the preceding communication.-E. Mathias : The destructive effects of lightning upon plants. A discussion of the cause of the observed fact that when a single tree is struck by lightning and killed, and the lesions on the tree are obvious, plants and trees within a certain radius of this tree also die, although there are no lesions to account for this.Edmond Sergent, A. Donatien, L. Parrot, and F. Lestoquard: Etiological considerations on north

No. 3205 , VoL. 127] 